Yar and. Bince the last report the patient had rapidly gined strength and muscular power. She walked this marning a distance of a mile, and back to the hospital, to hare a photographic likeness of herself taken, which is sont herewith, along with another which was taken previously to the operation being performed.

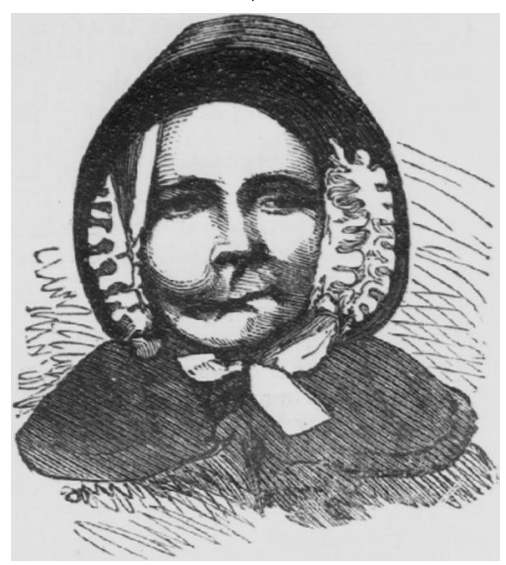

Appearance of patient vefore operatiou.

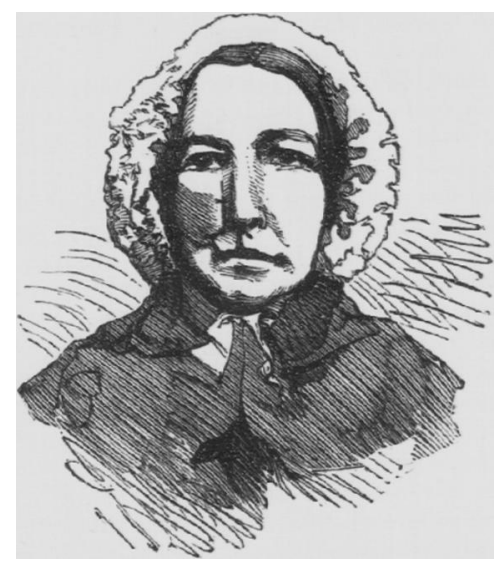

Appearance of patient after operation.

May 3rd. She was discharged from the hospital quite well.

The tumour was sent to be examined by Mr. Quekett, of the Royal College of Surgeons, who kindly transmitted the following opinion as to its nature:- "It appears to be wholly composed of fibrous tissue, which, in many situations, is being rapidly converted into bone; not bone of the kind usually occurring in fibrous tissues, but true bone, in which lacuna are very abundant."

Liverpool, May 8th, 1855.

\section{NOTES ON OPHTHALMIC DISEASES.}

By J. Vose SoloMoN, Esq., F.R.C.S., Surgeon to the Birmingham and Midland Counties Eye Infirmary ; formerly Honorary Surgeon to the Birmingham General Dispensary.

$$
\text { [Continued from page } 41 \% \text {.] }
$$

FATTY DEgenERATION OF THE LENS: A CASE IN WHICE ITUEROUS GOLD-LIKE OPACITIES (CHOLESTERIN) WERE DISSEMINATED IX A LENS THAT WAS, WITH THEBE EXCEPTIONS, TRANSPARENT : CATAKACTA BCINTILLANS : GPABKLING OR GOLD-LEAF CATARACT.

[Abstract of a paper read before the Queen's College MedicoChirurgical Society, January 4 th, 1853. The patient was examined by the members.?

Ir my paper on the Pathology of Foreign Bodies intruded within the Anterior Chamber of the Eye, it.was remarked that, in some of those accidents, the textures which first inflame are the choroid and retina; and that this was referrible either to their suffering concussion at the moment of the foreign body, or to their being, from some cause, the weaker structures, and consequently more susceptible of disease than the iris, which is, in the majority of cases, primarily inflamed. The narrative of the case of the young man, who presented himself for the inspection of the members of the Society, and who had also been examined by the clinical class at the Eye Infirmary, will illustrate one of the ways in which amaurosis will sometimes result from injury; and it will at the same time afford an instance of a most peculiar and rare form of lenticular degeneration- -80 rare, that at present no allusion has been made to it in the systematic works on ophthalmic surgery that have emanated from British surgeons, and which adorn the medical literature of this country.*

Case xix. Henry S., 23 years of age, a gun-lock filer at Wednesbury, of delicate appearnec, fair complexion, and with brown hair and irides, applied to the Birmingham Eye Infirmary Nov. 25th, 1852, on account of acute conjunctivosclerotitis and dimness of vision, the result of a blow from the flying up of a piece of his work. He said that he had lost the sight of the right eyc from a similar accident three years ago. I thcrefore considered his case important, and admitted him into the wards of the infirmary. The eje completely recovered.

Upon examining the right eye, which was amaurotic, in a clear light (the weather had hitherto been wet and cloudy), I discorered numerous minute shining bodies, of a golden colour, and as fine as grains of sand, scattered throughout the whole posterior part of the substance of the lens, which was in all other parts transparent. They were lustreless in the dark, and most evident in sun light; some of the bodies were planes. When the eye was quickly moved, a tremulous motion was imparted to them, but not to the iris. With this exception, they were stationary. The eyeball had lost its natural tension, indicating dissolution of the vitreous. The eyes appeared of equal size, but to the touch the right was less prominent. 'The posterior capsule of the lens was transparent; also the anterior one with the exception of the superior half, which was traversed transversely by four opaque lines, of the shape of bloodvessels, of which they were the remains. The choroidal pigment appeared of normal blackness. The pupil was cirpigmen natural size, insensible to light, and nearly so to belladonna and its alkaloid. The iris was of a darker brown, and perhaps thicker than that of the corresponding eye; and it had lost somewhat of its normal lustre and fibrous appearance. In its structure I noticed something like a forcign body. The aqueous body and cornen were pellucid. Upon the sclerotica were numerous pink ressels, some of which were tortuous; some were not so, but terminated abruptly in dark spots or points, about one-eighth of an inch from the margin of the cornea. These spots were the result of a varicose condition of the choroid veins. The conjunctiva was injected to a trifling degree. The surface of the left eye presented dilated muscular arteries: its vision was perfect.

History of the Right Eye. "Whilst engaged", said the patient, "three years ago (1849), in gun-lock filing, I received $a$ wound in the right eyeball from a portion of one of my tools, which broke in the using of it. The wound bled a little, but I do not know whether any metal penetrated within the eye. I was attended by a doctor, who applied leeches, etc., etc.; and, in about three or four weeks, pain and dimness of sight were removed. I could read, but a black oblong spot mored consentaneously with the cye, and somewhat interrupted my view of objects." The musca did not float about.

Two months after this period, the eye was inflamed, from exposurc to cold. Under medical treatment, it got well.

- This omigsion has been supplied in the present year (1855) bJ Mackenzie. 
" Fourteen weeks after the sccident, the vision became dim, a mint or fog appeared before it, and there was slight pain in the eje and forehead; but on this occasion there was not external redness. I again placed myself under treatment at the Institution; a consultation was held, and, as I thought, an unfarourable opinion entertained rogarding my case; and, consequently, I attended no more. The dimness of sight gradually increased up to March 1851, when it became stationary, the same as it is now, namely, incapable of determining colours, the number or form of a person's fingers, but cognisant of moving bodies of size."

Rexares. There cannot be a doubt, I conceive, that the peculiar disease that has taken place in the right lens of this patient is due to a subacute posterior internal ophthalmia, which gradually involved the whole of the internal structures.

The concussion sustained by the eyeball three years previously was in great measure recovered from at the end of twenty-one days' treatment; but the presence of a fixed musca afforded unequivocal evidence of insensibility of part of the retina. Moreover, we find the choroid and retina, which were probably, prior to the accident, the weaker textures (for, in gun-lock filing, the right eye would be more subject to overwork and to consequent congestion), had become so susceptible of disorder that, in fourteen weeks after the accident, symptoms of subacute posterior internal ophthalmia were manifested, and proceeded by slow but unerring gradations to the annihilation of useful vision.

Of the period at which the lens became affected we have $n 0$ facts for the formation of an opinion.

A peculiarity in the present case, distinguishing it from all others of the kind that have been recorded, with one exception, ${ }^{*}$ is, that the transparency of the front of the lens permitted the particles of cholesterin (such I shall presently prove to be their nature) to be observed in the exact position in which they originally were formed.

I have found in the public journals notes of seven cases in which shining bodies, resembling those I have described, were observed in the human eye; my own case will make eight.

In five instances they were noticed in the aqueous, and once in the vitreous, after an operation upon a lenticular, or a capsular cataract.

In six cases, the patient was amaurotic.

In two, the vision was good, but muscre volitantes were experienced; and in them the vitreous was the seat of the brilliant bodies. The lens was transparent in one of these last, in the other, depression had been performed seven years before, and followed by a capsular cataract; it was three weeks after the removal of the latter that the particles of cholesterin were descried moving up and down in the vitreous when the eye-ball was suddenly moved, $\dagger$ constituting the disease known as synchysis étincelant, or sparkling synchysis.

The rare opportunity of having one of this kind of cataracts analysed fell to the lot of Mr. Wilde. Professor Aldridge, who conducted the chemical examination, says, in a letter to that gentleman, "The crystals referred to, when examined by the microscope, appeared under the form of rhombic plates. They were soluble in ether, and hot alcohol, from the latter of which they recrystallized in cooling, and were insoluble in a solution of potash, which, however, removed their colour..... I think there can be no doubt but that the crystals were chiefly composed of cholesterine." $\ddagger$

Cholesterin cataract resists absorption much longer than the ordinary form of lenticular opacity. In an instance reported by Sichel, some of the particles were seen three jears after their first observation.

Birmingham, May 1855.

- A case by Parfait Lendraw, in the "Revue Médicale", tome iv, p. 203. Paria: 1828.

+ Desmarre, case in the "Annales d'Oculistique", Nov. 1845, p. 220.

+ Deamarre, case in the "Annales d'Oculistique", Nov. 18
Dublin Quartarly Journal of Med. Science, rol. v, p. 497.

\section{ON DIGITALIS IN NEURALGIA. \\ By JUNIUS HARDWICKE, Esq.}

Amorast all the remedies which hare been suggested for the cure of neuralgia, I can find no mention made of digitalis, except by Dr. Toogood Downing. This author, in his admirable prize essay on neuralgia, does name this drug, though, strange to say, he gives it a place last on the list of those which are to be tried in his new method of fumigating the part affected. He says, when speaking of this plan, "The plants I have chiefly employed have been various mixtures of belladonna, henbane, cocculus Indicus, tobacco, hops, aconite, stramonium, hemlock, digitalis," etc.

Now, the result of my experience during the last four or five years is the conclusion that digitalis giren internally is a most successful remedy in such cases, as I have not yet met with a single instance of its failure.

Several years ago, having been completely beaten by the case of a parish patient (and not knowing where to look next for some means of giving relief to the sufferer) who had just entered my surgery in the greatest agony, his eje watering, his cheek hot, pulse excited, etc., - I was induced to try some digitalis powder, which I had carefully prepared according to Pereira's directions, to subdue the increased nervous and arterial action of the part. He took half a grain in the form of pill every three hours, and came next day expressing great delight at his improvement, and begging some more of the pills, which he continued until he was cured.

Since this time, I have always used powdered digitalis in such cases with the happiest results, and have even prescribed it in cases where there was much debility, and where I much feared its depressing effects, without any dangerous symptoms. I have, however, more than once thought it prudent to suspend its use for a time before the pain was completely removed; and frequently I have found it necessary to produce a decided impression on the heart; but, in most instances, relief was obtained without using it so freely. The pills have obtained such repute amongst my patients that they often apply to me for my "tic pills".

I have used this medicine in a great many cases of spasmodic and rbeumatic neuralgia of the face; and, during the late spring, the many cases of this kind which have occurred have given a very fair trial of its efficacy. In the case of neuralgia of the arm, I tried it with decided benefit.

Rotherham, Yorkshire, Mra 1855.

\section{BIBLIOGRAPHICAL NOTICES.}

A System of Instruction in Qualitative Chemicat Axalysis. By Dr. C. Remigius Fresenios, Professor of Chemistry and Natural Philosophy, Wiesbaden. Fourth Edition, edited by J. Lloyd Bullock, F.C.S. pp. 310. London: 1855.

AT the very close of last year, it was our duty-and our duty is very pleasing in such instances, in spite of the quantum which may cling to our own selves, of the inbred malignity people are taught to believe to be the attribute of our craft - to pronounce no high-flown, but a wellweighed and favourable judgment on the Quantitative Analysis of Professor Freserius-a book which had been most carefully and creditably clothed in an English dress by Mr. Lloy D Bullock.

A few months have elapsed, and this latter gentleman has completed his task by placing in our hands a translation of the same professor's Instructions in Qualitative Chemical Analysis, from the last, the eighth German edition of this excellent treatise; and has thus merited praise for industry at the least, which praise, we are pleased to state, has not been won at the expense of accuracy. We have looked very carefully through many of the pages of this book, in order to detect an error; and we hare the mare 